\title{
Dynamic simulation of the Cape Barren Island fire using the Spark framework
}

\author{
J. J. Sharples $^{\text {a }}$, R. Richards ${ }^{\text {b }}$, J.E. Hilton ${ }^{\text {c }}$, S. Ferguson ${ }^{\text {b }}$, R.C.Z. Cohen ${ }^{\text {c }}$ and M. Thatcher ${ }^{\mathrm{d}}$

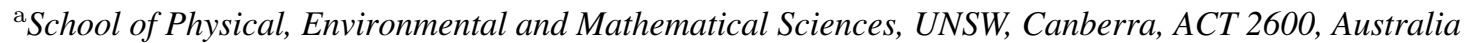 \\ ${ }^{\mathrm{b}}$ Tasmanian Fire Service, Hobart, Tasmania 7001

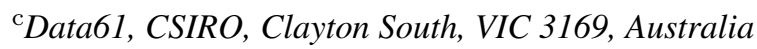 \\ dOceans \& Atmosphere, CSIRO, Aspendale, VIC 3195, Australia \\ Email: j.sharples@adfa.edu.au
}

\begin{abstract}
The Cape Barren Island fire occurred in December 2016 and ran mostly unsuppressed from the west to the east of the island, burning around $60 \%$ of the island's total area. The fire offered valuable opportunities for the evaluation and development of fire spread simulators as it ran through relatively uniform fuels subject to minimal suppression.

In this study we simulated the evolution of the Cape Barren Island fire using the Spark framework. The framework allows rates of spread in different fuel types and new types of dynamic fire behaviour to be easily tested. Here, we incorporate parameterised behaviour models including one that allows for the effect of vorticity-driven lateral spread (VLS). In VLS regions fires are counter-intuitively observed to spread perpendicular to the wind direction on lee slopes due to vortex iteration with the terrain. The VLS sub-model was implemented natively using the Spark framework using a filter criteria and a specialised rate-of-spread model for fire propagation perpendicular to the wind direction. This dynamically-driven mode of fire propagation is not accommodated within the current suite of operational fire spread simulators. Indeed, this work presents the first instance of a two-dimensional fire spread simulator that incorporates VLS dependence.
\end{abstract}

The simulations were found to closely match observed fire perimeters over a 45 hour duration, apart from regions in which suppression operations had likely occurred. The simulations also served as a validation exercise for the heathland fuel rate-of-spread model used, showing the empirical model has excellent predictive ability. Simulations performed with the VLS sub-model were found to match observed fire perimeters in regions where VLS was predicted to occur. Furthermore, simulations performed without the VLS sub-model were found not to burn these same regions. The accuracy of the simulated fire perimeters were evaluated using the 'threat score' (Faggian et al., 2017), which measures how well the simulated burnt area overlaps with the observed burnt areas. The threat score is calculated as:

$$
S=\frac{T P}{T P+F P+F N}
$$

where $T P$ represents the total area that the simulated fire correctly identified as burnt (true positives), $F P$ represents the total area that the simulated fire incorrectly identified as burnt when it was observed as unburnt (false positives), and $F N$ represents the total area where the simulated fire did not spread but was observed to have burnt (false negatives).

Threat scores were calculated at two times when observed fire perimeter data was available: 11:30 am on $6^{\text {th }}$ Dec, and 9:00 am on $7^{\text {th }}$. At the earlier time the threat scores were $S=0.4768$ for the simulations without the VLS sub-model, and $S=0.4788$ for the simulations with the VLS sub-model. At the later time the threat scores were $S=0.7393$ for the simulations without the VLS sub-model, and $S=0.7434$ for the simulations with the VLS sub-model. Hence, inclusion of the VLS sub-model resulted in a slight improvement in overall model performance.

Extension of fire spread simulators to accommodate fire behaviours such as VLS offer an enhanced ability to predict critical aspects of fire development, with ensuing benefits to fire managers, firefighter safety and resilience of the broader community.

Keywords: Wildfires, sensitivity, modelling 


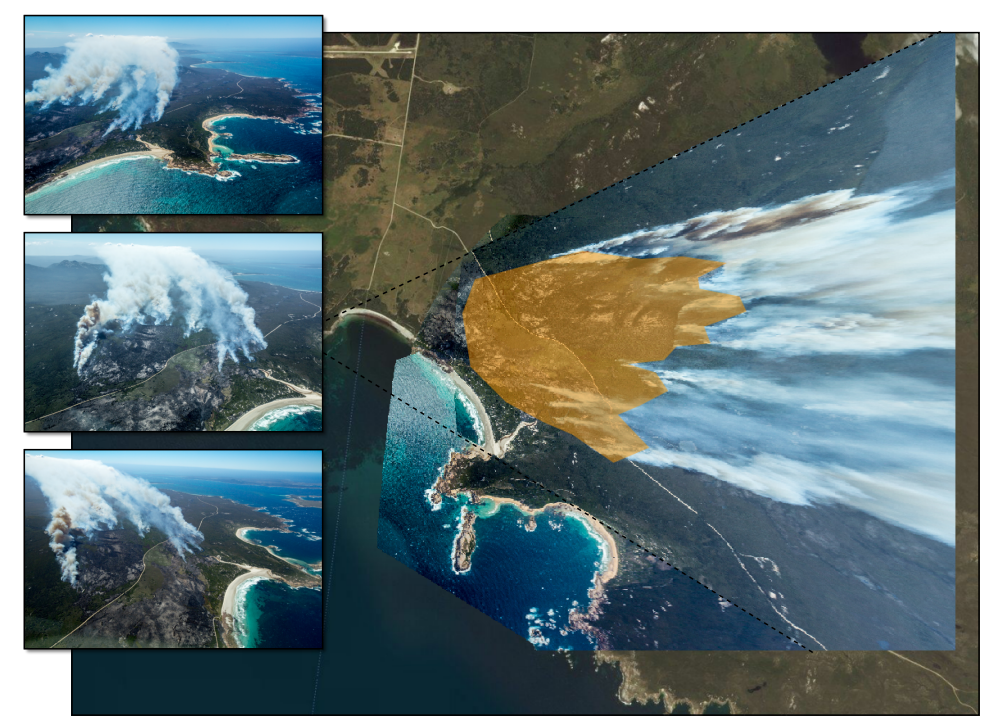

Figure 1. Cape Barren Island fire aerial images (courtesy Sammi Gowthorp), showing the active perimeter at the western end of the island near Thunder and Lightning bay. The three inset pictures show different views of the fire, timestamped at 12:15 pm on the $5^{\text {th }}$ December. The large image shows the three images georectified onto the ground plane and the manually identified active fire perimeter in orange.

\section{INTRODUCTION}

Cape Barren Island is a sparsely populated island in Bass Strait, off the north-east coast of Tasmania with a total area of around $500 \mathrm{~km}^{2}$. In December 2016 a large fire burnt with minimal suppression across the entire length of the island under predominately westerly winds. While suppression activities occurred around inhabited areas and roads on the northern flank of the fire, most of the fire was allowed to run unsuppressed. The fire was first reported around $10 \mathrm{pm}$ on the $4^{\text {th }}$ De cember 2016 at the we stern end of the is land, near Thunder and Lightning Bay. The fire burnt until 8 December 2016, when it was suppressed by around $8 \mathrm{~mm}$ of rain falling on the island. The total area burn was reported as 30,780 ha or about $64 \%$ of the island's area. The fire burnt in fuels that were predominantly coastal heath, but which also comprised pockets of eucalypt forest on the more hilly portions of the island.

As much of the spread of the fire observed across the island occurred as natural progression, the 2016 Cape Barren Island fire provides a valuable case study to evaluate the performance of fire spread simulators in the fuel types and topography features of the island. A large data set was collated on the fire by the Tasmania Fire Service, including reconstructed perimeters over several days, incident reports detailing suppression and photographs of burnt and un-burnt fuel just after the event. Additionally, a fortunate series of aerial photographs taken by a local resident provide detailed information on the fire perimeter just after the fire was fully established on the morning of the $5^{\text {th }}$ December. These images were kindly shared with the authors, allowing us to closely reconstruct the fire perimeter using georectification from known ground co-ordinates in the images. A series of these aerial images is shown in Fig. 1 along with the resulting georectified image and manually estimated fire perimeter.

The fire perimeter at 1 1:30am, $6^{\text {th }}$ December 2017 is s hown in F ig. 2 . Of particular note is the pattern of fire spread evident in the circled $r$ egion. Despite the westerly winds under which the fire was being driven, this part of the fire exhibits marked spread towards the north, in a direction transverse to the prevailing winds. Instances of lateral spread of a fire across the prevailing winds under similar conditions have been identified and discussed (Simpson et al., 2013). In particular, in a number of instances pyrogenic vorticity has been identified as the main driver of lateral spread across steep, leeward slopes in a phenomenon known as Vorticity-driven Lateral Spread (VLS). Given the pattern of lateral spread evident in Fig. 2 it is therefore natural to question whether it is a consequence of VLS.

In this study we attempted to reproduce the Cape Barren Island fire using the Spark fire simulation toolkit. The rate-of-spread models for the fuel types found on the island, such as heathland, are tested as well as dynamic models such VLS and Kataburn slope correction models (Sullivan et al., 2014). 


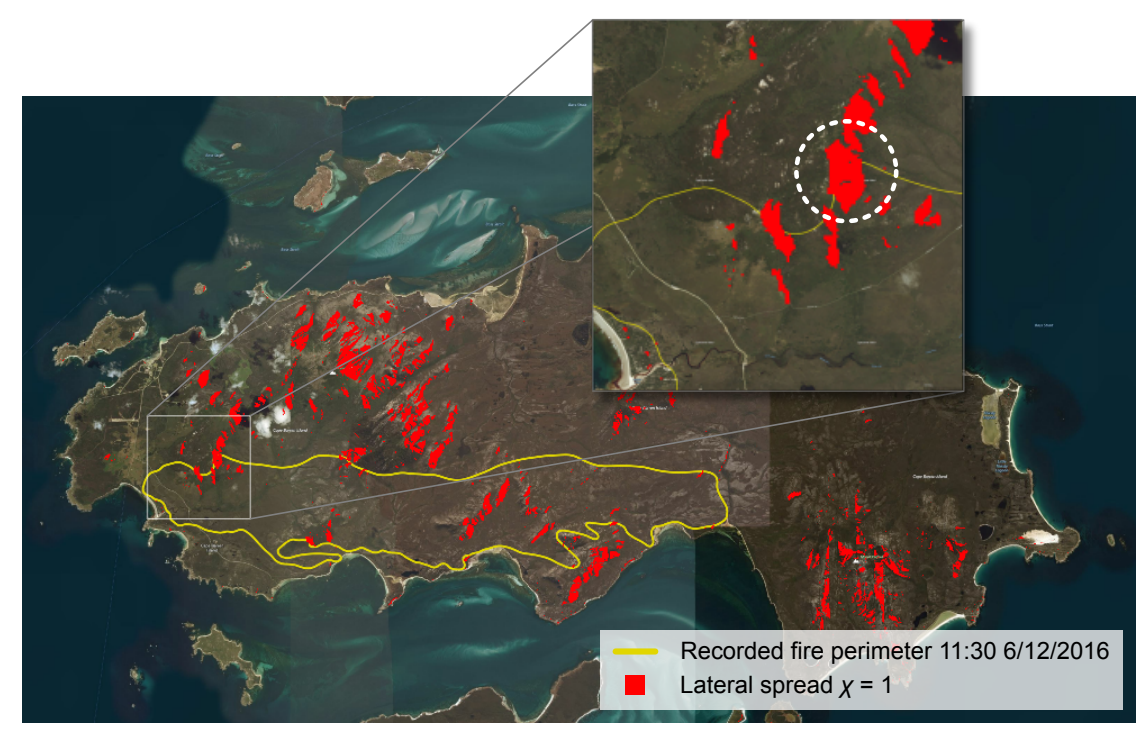

Figure 2. Cape Barren Island with first fire isochrone and areas of $\chi=1$ shown in red.

\section{METHODOLOGY}

\subsection{Spark fire simulations}

Spark is a simulation toolkit for predicting fires, comprising a general perimeter evolution model and geospatial analysis tools. The main strength of the framework is configurability, with users free to choose which rateof-spread and dynamic models to implement (Hilton et al., 2015). These models are implemented using a script in an extended version of the ' $\mathrm{C}$ ' language. The perimeter propagation model in Spark is level set based which allows the speed of the perimeter to be defined at every point as well as the merging and creation of any number of fires without additional computational cost. This is in comparison to older elliptical front tracking methods in which a generalised perimeter speed cannot be used and merging of perimeters is a computationally expensive operation (Sullivan, 2009).

The fire perimeter is updated in Spark using a user-defined rate of spread model depending on the local fuel classification. For practical applications these rate-of-spread models are empirically determined published models relating the head fire speed to fuel condition (such as fuel load and moisture levels) and local weather variables (such as temperature, wind direction and speed). In this study five different fuel types were accounted for using different empirical rate of spread models. These were the McArthur Dry Eucalypt model (McArthur, 1967), the Vesta Dry Eucalypt model (Cheney et al., 2012), the Marsden-Smedley buttongrass moorland model (Marsden-Smedley and Catchpole, 1995), the Anderson heathland model (Anderson et al., 2015) and the CSIRO grasslands model (Cheney et al., 1998).

Terrain effects can be incorporated into the simulations using a dynamic model. Here the McArthur model is used for the upslope correction, and the Kataburn model is used for the downslope correction (Sullivan et al., 2014). These models increase or decrease the rate of spread depending on the local slope angle with respect to the fire perimeter, $\phi$, in degrees. This was implemented as:

$$
\phi=\max \left(-20, \min \left(20, \frac{180}{\pi}\left(\tan ^{-1}(\hat{\mathbf{n}} \cdot \nabla h)\right)\right)\right)
$$

where $\hat{\mathbf{n}}$ is the normal vector of the fire perimeter and $h$ is the ground elevation. The slope angles are capped at $\pm 20^{\circ}$. The rate of spread on flat ground, $r$, is then modified to taken into account slope effects, $r_{s}$ by:

$$
r_{s}=r \times \begin{cases}2^{(0.1|\phi|)}, & \phi \geq 0 \\ \frac{2^{(0.1|\phi|)}}{2^{(0.1|\phi|+1)}-1}, & \phi<0\end{cases}
$$




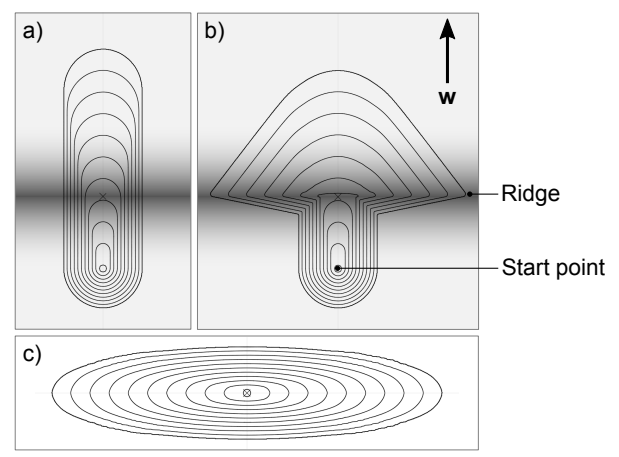

Figure 3. Dynamic VLS model example implemented in Spark showing plan view of fire isochrones spreading from a starting point over a ridge. a) Basic rate of spread model without VLS. b) VLS model incorporating VLS, where the fire spreads perpendicular to the wind direction on the lee side of the ridge. c) Elliptical spread in the direction perpendicular to the wind with the elliptical speed function defined in Eq. 7

A dynamic self-extinguishing model was also used in the simulations. The fire line intensity, $I$, in $\mathrm{kW} \mathrm{m}^{-1}$ was calculated at each time step using Byram's formula:

$$
I=0.1 H w r_{s}
$$

where 0.1 is a factor to convert fuel load $w$ from $\mathrm{t} \mathrm{ha}^{-1}$ to $\mathrm{kg} \mathrm{m}^{-2}$ and $H$ is the heat of combustion, estimated to be $18,000 \mathrm{~kJ} \mathrm{~kg}^{-1}$ for all fuels. The fire was assumed to extinguish under the conditions $t_{\text {burn }}>2$ hours and $I<120 \mathrm{~kW} \mathrm{~m}^{-1}$.

\subsection{Vorticity-driven Lateral Spread (VLS) dynamic model}

Sharples et al. (2012) introduced a wind-terrain filter that identified regions of the landscape prone to VLS occurrence for a given wind direction. In these regions the fire has been counter-intuitively observed to propagate in a direction perpendicular to the wind direction due to vortex formation on the lee slope. The necessary conditions for VLS occurrence on leeward slopes have been found to include: 1) Lee slope angle in excess of about $20-25^{\circ}$. 2) Aspect of lee slope aligns to within $30-40^{\circ}$ of the wind direction. 3 ) Wind speeds in excess of about $20 \mathrm{~km} \mathrm{~h}^{-1}$. 4) Forest fuels, with fuel loads of about 15-20 ha.

To include VLS as a dynamic model in Spark a binary value, $\chi$, was calculated at each time step which took the value 1 in regions prone to VLS occurrence and 0 elsewhere:

$$
\chi(\sigma, \delta)= \begin{cases}1, & \frac{180}{\pi} \tan ^{-1}(|\nabla h|)>\sigma \text { and } \theta \leq \delta \\ 0, & \text { otherwise }\end{cases}
$$

where $h$ is the ground elevation and $\theta$ is the angle between the downslope direction and the normalised local wind vector $\hat{\mathbf{w}}$, and is defined by:

$$
\theta= \begin{cases}\cos ^{-1}\left(-\frac{\nabla h}{\|\nabla h\|} \cdot \hat{\mathbf{w}}\right), & \|\nabla h\|>0 \\ \pi, & \text { otherwise }\end{cases}
$$

The parameters $\sigma$ and $\delta$, which define the VLS filter, represent threshold values for the topographic slope and $\theta$, respectively. Only parts of the landscape with slopes greater than $\sigma$ and with $\theta$ less than $\delta$ are prone to the VLS phenomenon. The values $\sigma=10.5^{\circ}$ and $\delta=40^{\circ}$ were found to be appropriate under a wide range of conditions, although for an elevation map of $250 \mathrm{~m}$ resolution. Although the filter may show some sensitivity to the finer spatial resolution of the elevation map used in this study, the differences were generally expected to be small and these values were used in this study.

The VLS model was implemented in Spark by using the standard rate of spread model for the fuel type in regions where $\chi=0$. In regions where $\chi=1$ the rate of spread was modified to spread in the direction perpendicular to the wind. The outward normal speed, $s_{\text {lat }}$, of the fire perimeter in these regions was set to: 

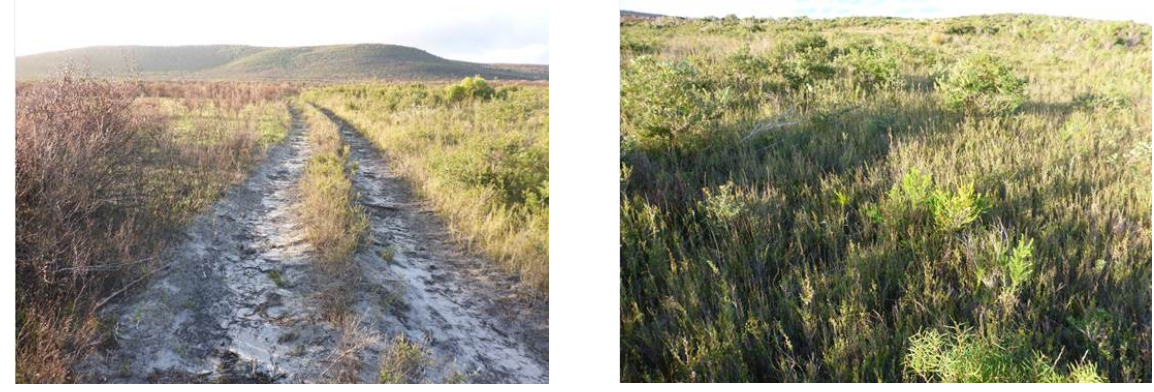

Figure 4. Cape Barren Island fuels courtesy of Lyell Dean, TFS.

$$
s_{\text {lat }}=k \sqrt{1-(\hat{\mathbf{n}} \cdot \hat{\mathbf{w}})^{2}+\epsilon},
$$

which creates an ellipse with the long axis perpendicular to the wind direction, where $k$ is a scaling parameter for the outward speed of the ellipse, $\hat{\mathbf{n}}$ is the normal to the perimeter and $\epsilon$ is parameter controlling the ellipticity. In practice a small value of $\epsilon \approx 0.1 k$ was required to ensure stable outward growth in the level set method. An example with a greatly exaggerated lateral rate of spread is shown in Fig. 3 for illustration. The difference between a basic rate of spread, Fig. 3a, and the same rate of spread with the dynamic VLS model included, Fig. $3 \mathrm{~b}$ can be seen by comparing the isochrones. The isochrones from the rate of spread for only elliptical growth given by Eq. (7) is shown in Fig. 3c. The Cape Barren Island fire simulations in this study were performed both with and without the VLS dynamic model to assess the model implementation for much more realistic fire spread rates.

\subsection{Model inputs}

The meteorological data required for the simulation included the $10 \mathrm{~m}$ wind strength and direction, air temperature and relative humidity. This data was derived from a downscaling reanalysis using the CSIRO Cubic Conformal Atmospheric Model (CCAM) (McGregor, 2005). CCAM can provide high resolution data over an area of interest using multiply nested variable resolution grids (Thatcher and McGregor, 2009). Here, the area of interest was centred on Cape Barren Island at $148.204^{\circ} \mathrm{E}$ and $40.398^{\circ} \mathrm{S}$. ERA-Interim reanalyses were dynamically downscaled via simulations of resolution $64 \mathrm{~km}, 8 \mathrm{~km}, 1 \mathrm{~km}$ to give final a data set at $500 \mathrm{~m}$ resolution over the island. The CCAM simulations were starting at the beginning of the month, with nudging from the scale-selective filter every 6 hours for surface pressure and winds and air temperature above $850 \mathrm{hPa}$. Output was saved at $5 \mathrm{~min}$ intervals for the fire spread simulations.

Although multiple fuel models were implemented the fire was found to burn almost entirely through coastal heathland and only a small portion of eucalypt forest. Some pictures taken by the Tasmania Fire Service shortly after the fire provided accurate information on structure and approximate characteristics of the fuel, shown in Fig. 4. Using these photos the fuel height used in the Anderson et al. (2015) model was estimated as $1.5 \mathrm{~m}$. To the authors knowledge the heathland model has not previously been used in a predictive two-dimensional simulation and this fire provided an excellent test of the predictive ability of the model.

The starting condition for the fire was reconstructed from aerial images of the fire. These were georectified using OpenCV by picking known ground points on the images and calculating the camera calibration parameters which were used to warp from image space to ground space (Bradski, 2000). The outline of the fire was manually traced into a geospatial shape file to provide a starting perimeter for the simulation. The simulations were run at $45 \mathrm{~m}$ resolution for a duration of 45 hours from this starting condition.

\section{RESULTS}

Comparisons between the simulations with and without the VLS model against the two available observed fire perimeters at 11:30 a.m. on the $6^{\text {th }}$ Dec and 09:00 a.m. on the $7^{\text {th }}$ Dec are shown in Fig. 5. Overall the extent in the easterly direction matches well, showing the Anderson et al. (2015) model very accurately predicts head fire speeds. The simulation on the $6^{\text {th }}$ Dec shows a good match on southern flank, but a wind change appears to have occurred in downscaled data moving the fire footprint to the north. Unfortunately no nearby weather stations on the island were able to investigate the timing of the wind changes. The observed and simulated 

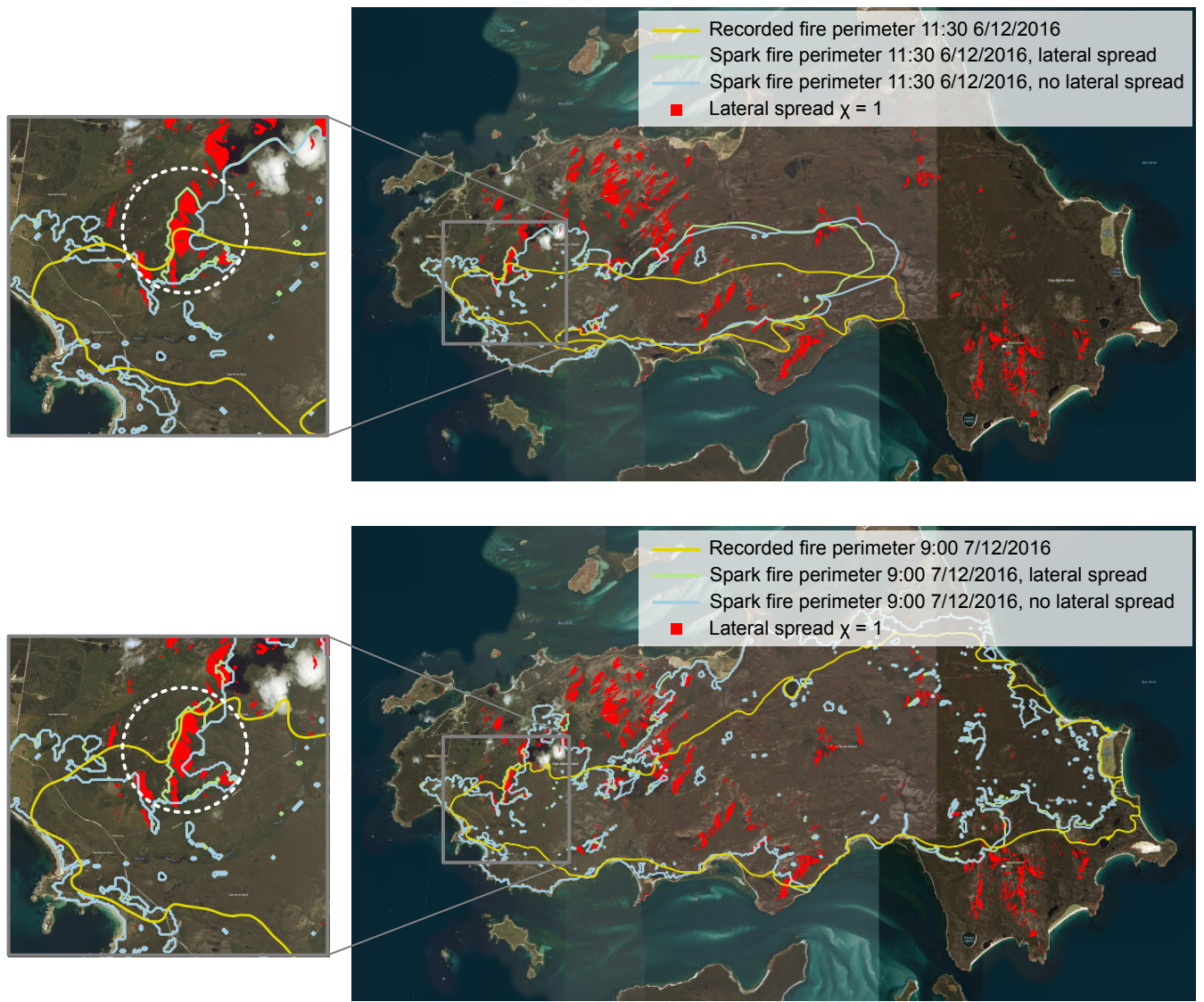

Figure 5. Spark simulations of Cape Barren Island fire, showing isochrones with and without lateral spread model in comparison to recorded fire perimeters and areas of $\chi=1$ shown in red.

perimeters match well on the $7^{\text {th }}$ Dec, except on the northern flank. This flank was subject to suppression along the roads and inland tracks, for example, the observed northern flank coincides with a road, which was likely used as a control line for successful suppression action. This was not taken into account in the simulations, which subsequently over-predicted the spread in the northerly direction. Overall, the simulations without the VLS sub-model produced a threat score (Faggian et al., 2017), of 0.4768 at 11:30 am on $6^{\text {th }}$ Dec, and 0.7393 at 9:00 am on $7^{\text {th }}$ Dec. In comparison, the simulations with the VLS sub-model produced corresponding threat scores of 0.4788 and 0.7434 , respectively, slightly higher than without the VLS sub-model.

Detailed consideration of the fire spread in regions of likely VLS occurrence are shown in the zoomed insets of Fig. 5. A lateral development of fire on the $6{ }^{\text {th }}$ Dec can be seen as a growth in the observed isochrones in a northerly direction perpendicular to the wind (circled). Given this occurs within a region of eucalypt woodland and is identified by the VLS filter it is highly likely that this lateral development is a VLS ev ent. Overall the simulation isochrones with and without the VLS model are similar. However the lateral development of fire on the $6^{\text {th }}$ Dec is completely missed by the simulation without the VLS parametrisation. Furthermore, the simulation without the VLS model can be seen to not extend at all into this region in the results on the $7^{\text {th }}$ Dec.

\section{DISCUSSION AND CONCLUSIONS}

We carried out simulations of Cape Barren Island fire using the Spark framework incorporating multiple fuel models and dynamic models for slope correction, self extinguishing and a VLS model. This is the first time a VLS model has been used in a large scale dynamic fire s imulation. Simulations were performed with and without the VLS model to test the effectiveness of the model in a predictive context.

The overall results from Spark compared well to observed fire isochrones, although minor differences in timings of wind changes affected the fire extent on the northern flank after a simulation period of one day. Major differences were found in comparison to observations after two days along the northern flank, although these differences were almost certainly from reported suppression operations which were not taken into account 
in the simulation. Elsewhere the simulated and observed perimeters showed a close match after a 45 hour simulation period showing that the rate-of-spread models used, predominately the heathland model, provided excellent predictive ability for these fuel types.

The observed fire perimeter indicated the possibility that occurrence of VLS events in the early stages of the fire affected the propagation. This possibility was supported by the fact that the simulator was better able to capture the observed spread in these regions when the VLS sub-model was incorporated. Although differences in simulated perimeters with and without the VLS model were relatively minor, the simulations with the dynamic VLS model agreed with the observed perimeters, whereas the simulations without the model showed no fire spread into these regions.

Despite the small role of VLS in the overall development of this particular fire, there are numerous cases where it has had more significant effects in larger fires. The insights provided from this study provide a platform for further development of models that accommodate dynamic behaviours. Such a platform may enhance the ability of fire agencies to manage fires to better protect communities and manage risk during bushfire events.

\section{REFERENCES}

Anderson W.R., Cruz M.G., Fernandes P.M., McCaw L., Vega J.A., Bradstock R.A., Fogarty L., Gould J., McCarthy G., Marsden-Smedley J.B., Matthews S., Mattingley G., Grant P. H., van Wilgen B.W. (2015). A generic, empirical-based model for predicting rate of fire spread in shrublands. International Journal of Wildland Fire, 24, 443-460.

Bradski G. (2000). The OpenCV library, Doctor Dobbs Journal, 25, 120-126.

Cheney N.P., Gould J.S., Catchpole W.R. (1998). Prediction of fire spread in grasslands, International Journal of Wildland Fire, 8, 1-13.

Cheney N.P., Gould J.S., McCaw W.L., Anderson W.R. (2012). Predicting fire behaviour in dry eucalypt forest in southern Australia, For. Ecol. Manag., 280 120-131.

Faggian N., Bridge C., Fox-Hughes P., Jolly C., Jacobs H., Ebert B., Bally J. (2017), Final Report: An evaluation of fire spread simulators used in Australia, Bureau of Meteorology.

Hilton J.E., Miller C., Sullivan, A.L., Rucinski C. (2015). Effects of spatial and temporal variation in environmental conditions on simulation of wildfire spread, Environmental Modelling and Software, 67, 118127.

Marsden-Smedley, J.B., Catchpole, W.R. (1995). Fire modelling in Tasmanian buttongrass II. Fire behaviour International Journal of Wildland Fire, 5, 215-228.

McArthur, A.G. (1967). Fire behaviour in eucalypt forest. Commonwealth Department of National Development. Forestry Timber Bureau, Leaflet 107, Canberra, ACT.

McGregor, J. (2005). C-CAM: Geometric Aspects and Dynamical Formulation, CSIRO Atmospheric Research Technical Paper No 70, 43.

Sharples J.J., McRae R.H.D., Wilkes S.R. (2012). Wind-terrain effects on the propagation of large wildfires in rugged terrain: fire channelling. International Journal of Wildland Fire, 21, 599614.

Simpson C.C., Sharples J.J., Evans J.P., McCabe M.F. (2013). Large eddy simulation of atypical wildland fire spread on leeward slopes. International Journal of Wildland Fire, 22, 282296.

Sullivan, A.L. (2009). Wildland surface fire spread modelling, 19902007. 3: Simulation and mathematical analogue models, International Journal of Wildland Fire, 18, 387-403.

Sullivan, A.L., Sharples, J.J., Matthews, S., Plucinski, M.P. (2014). A Downslope Fire Spread Correction Factor Based on Landscape-scale Fire Behaviour, Environmental Modelling and Software, 62, 153-163.

Thatcher M., McGregor J. (2009). Using a scale-selective filter for dynamical downscaling with the conformal cubic atmospheric model, Mon. Wea. Rev., 137, 1742-1752. 